\title{
Implementasi Metode Fast Fourier Transform (FFT) Dalam Mengklasifikasikan Suara Pria dan Wanita di Laboratorium Jurusan Teknik Elektro Politeknik Negeri Balikpapan
}

\author{
Andi Sri Irtawaty ${ }^{1 *}$, Maria Ulfah ${ }^{2}$, Silfi Fakhirotul Rukhyah ${ }^{3}$ \\ ${ }^{1 *, 2,3}$ Politeknik Negeri Balikpapan \\ *andi.sri@poltekba.ac.id
}

\begin{abstract}
The Fast Fourier Transform (FFT) method is a method used to represent a sound signal in a discrete time domain into a sound signal in the frequency domain [1]. FFT is a derivative of the DFT equation where the number of digital calculations on the DFT can be significantly reduced so that with the discovery of the FFT, digital calculations of frequency spectrum can be realized simply in its implementation [2]. In this study, there will be a test of 10 sound samples recorded in the wav format, and the ultimate goal is to develop a learning media for signal processing courses in the laboratory of the Balikpapan State Polytechnic Electrical Engineering Department. The parameters used are amplitude, period, magnitude, and sound signal power. The results of testing of the four parameters turned out that only the amplitude and power parameters were very accurate in distinguishing characteristics between male and female voices, namely in male voices having higher amplitude and power than female voices, so it can be concluded that the accuracy of the FFT method is in classify male voice and female voice by $90 \%$.
\end{abstract}

Keywords: Human voice, Signal, Amplitude, Periode, power, FFT

\begin{abstract}
Abstrak
Metode Fast Fourier Transform (FFT) merupakan suatu metode yang digunakan untuk merepresentasikan sinyal suara dalam domain waktu diskrit menjadi sinyal suara dalam domain frekuensi [1]. FFT merupakan turunan dari persamaan DFT dimana jumlah perhitungan digital pada DFT dapat dikurangi secara significant sehingga dengan adanya penemuan FFT maka perhitungan digital terhadap spektrum-spektrum frekuensi dapat diwujudkan secara sederhana dalam implementasinya [2]. Dalam penelitian ini, akan dilakukan pengujian terhadap 10 sampel suara yang direkam dalam format .wav, dan tujuan akhirnya adalah untuk mengembangkan media pembelajaran mata kuliah pengolahan sinyal di laboratorium Jurusan Teknik Elektro Politeknik Negeri Balikpapan. Adapun parameter yang digunakan adalah amplitudo, periode, magnitudo, dan daya sinyal suara. Hasil pengujian dari keempat parameter tersebut ternyata hanya parameter amplitudo dan daya yang sangat akurat dalam membedakan ciri antara suara pria dan suara wanita yaitu pada suara pria memiliki nilai amplitudo dan daya yang lebih tinggi daripada suara wanita, sehingga dapat disimpulkan bahwa tingkat keakuratan metode FFT ini dalam mengklasifikasikan suara pria dan suara wanita sebesar $90 \%$.

Kata kunci: Suara manusia, sinyal, amplitudo, periode, daya, FFT
\end{abstract}

\section{Pendahuluan}

Suara dapat menjadi ciri khas yang membedakan antara individu satu dengan yang lainnya, seperti fingerprint (identifikasi pola sidik jari pada setiap orang), retina scan (identifikasi berdasarkan pola pembuluh darah pada retina mata), face recognition (pengenalan seseorang berdasarkan raut dan ekspresi seseorang dengan kunci utama pada letak wajah dan mulut) [4]. Dalam pengenalan atau identifikasi terhadap suara manusia, tidak semua pendengaran manusia mampu 
membedakan suara dari masing-masing individu yang dikenalnya. Kepekaan telinga juga memiliki berbagai keterbatasan dan sensitif terhadap amplitudo dari suara asal [5]. Dalam penelitian ini, akan digunakan metode Fast Fourier Transform (FFT) yaitu suatu model transformasi yang memindahkan sinyal domain waktu menjadi sinyal domain frekuensi [1]. Jadi rumusan masalah dalam penelitian ini adalah sebagai berikut:

1. Bagaimana mengkasifikasikan suara wanita dan suara pria dengan metode FFT.

2. Parameter apa saja yang menjadi tolok ukur dalam pengklasifikasian tersebut.

3. Berapa persen tingkat keakuratan dari metode FFT tersebut.

Berdasarkan rumusan masalah tersebut, maka dalam penelitian ini akan dibuat sebuah simulasi berbasis matlab yang akan menampilkan bentuk gelombang sampel suara manusia dalam 2 dimensi beserta parameterparameternya. Tujuan akhir dari penelitian ini adalah untuk mengembangkan media pembelajaran di bidang telekomunikasi khususnya untuk penyempurnaan praktikum pada mata kuliah Pengolahan Sinyal.

\section{Metoda Penelitian}

\subsection{Metode Fast Fourier Transform (FFT)}

Metode yang digunakan dalam penelitian

ini adalah metode FFT, Tahapan dalam penelitian ini meliputi:

1. Tahap I (Persiapan)

Tahap ini meliputi tahapan studi literatur dari permasalahan yang dikemukakan, Studi literatur diperoleh dari buku, jurnal, artikel laporan penelitian dan situs dari internet, Dalam tahapan ini dilakukan proses pengumpulan data primer (data pakar) dari beberapa literatur. Salah satu data pakar menjelaskan bahwa daya sinyal terkuat untuk sampel suara wanita berada pada range antara 64,61 dB hingga 65,95 $\mathrm{dB}$ dan daya sinyal terendah diperoleh pada range antara sebesar 57,35 $\mathrm{dB}$ hingga 58,51 dB. Sedangkan pada gender laki-laki, daya sinyal terkuat berada pada range antara 58,65 $\mathrm{dB}$ hingga $60,68 \mathrm{~dB}$ dan daya sinyal terendah berada pada range antara 52,51 dB hingga 54,41 dB. [3].

2. Tahap II (Penelitian)

Langkah - langkah dari tahap ini meliputi :

a) Proses perekaman 10 sampel suara untuk pengucapan "Pengolahan Sinyal" lalu disave dalam format.wav ;

b) Apabila fasilitas hp android yang digunakan dalam format mp3, maka sampel suara yang direkam harus dikonversi ke format wav menggunakan aplikasi format factory sehingga dapat ditampilkan bentuk gelombangnya menggunakan program aplikasi matlab.

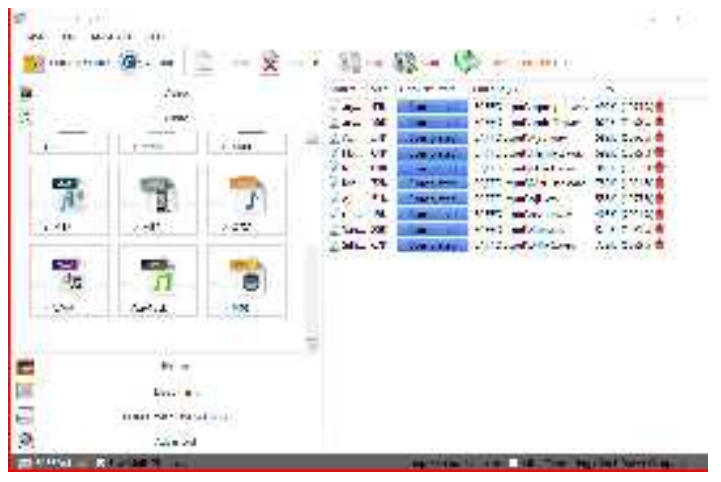

Gambar 1. Suara dalam Format wav

c) Hasil tampilan bentuk gelombang / sinyal dari sample suara tersebut adalah dalam 2 dimensi.

d) Selanjutnya merata-ratakan parameter amplitudo dan periode dari bentuk gelombang sampel suara untuk pengucapan "Pengolahan Sinyal".

e) Menampilkan magnitudo sinyal terhadap frekuensi sampling yang telah ditentukan berdasarkan hasil perhitungan periode sinyal.

f) Menghitung daya sinyal dalam dB.

3. Tahap III (Analisis Data)

Pada tahap ini, akan dianalisa perbedaan ciri suara pria dan wanita dewasa berdasarkan parameter amplitudo, periode, magnitudo, dan daya sinyal suara. 
4. Tahap IV (Kesimpulan)

Berdasarkan hasil analisa data, dari 4 parameter (amplitudo, periode, magnitudo, dan daya sinyal suara) yang diujikan pada 10 sampel suara manusia, ternyata hanya 2 parameter (amplitudo dan daya sinyal suara) yang sangat akurat dalam mengklasifikasikan suara pria dan suara wanita.

\subsection{Perancangan Flowchart metode klasifikasi ciri sampel suara wanita dan pria berbasis FFT.}

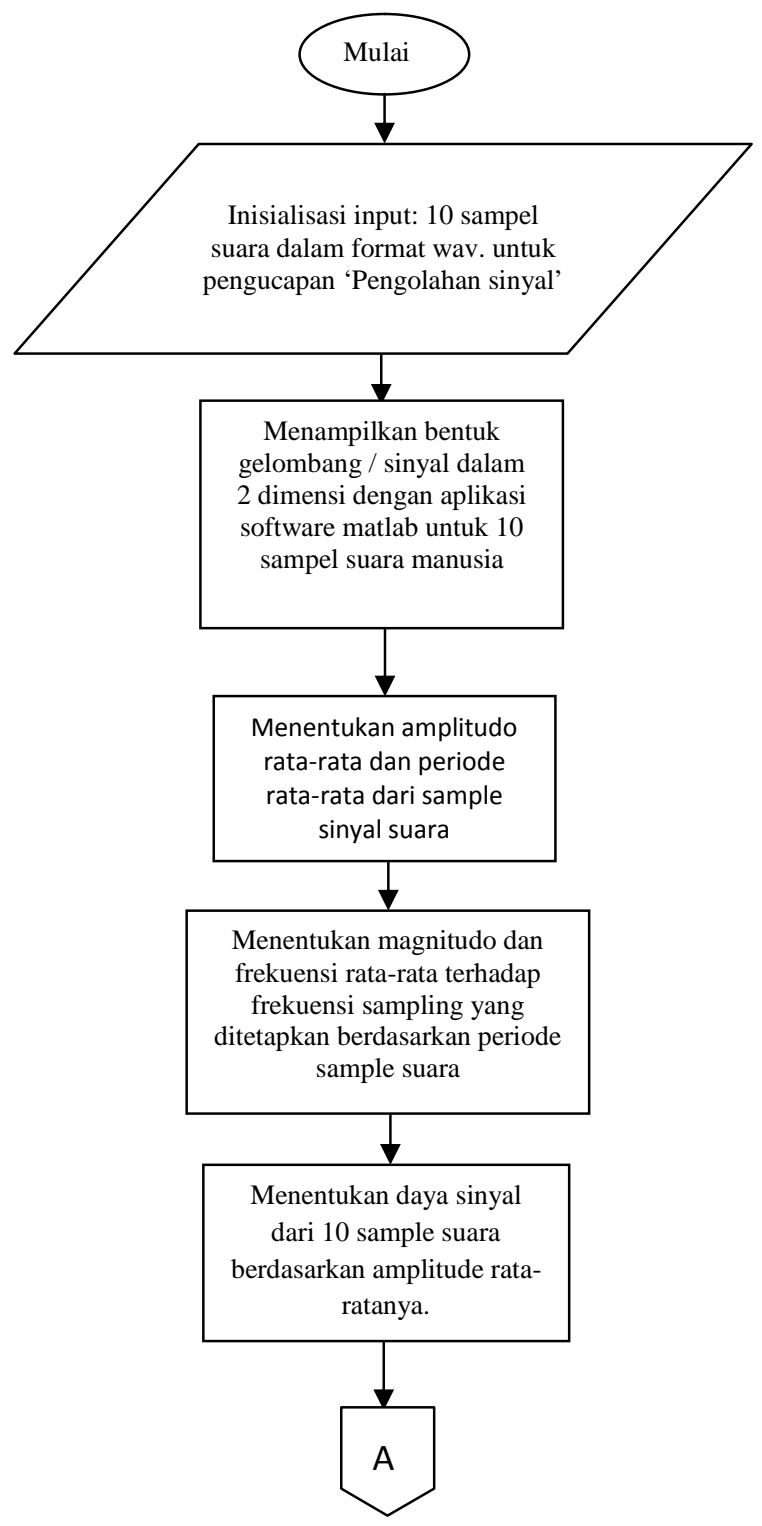

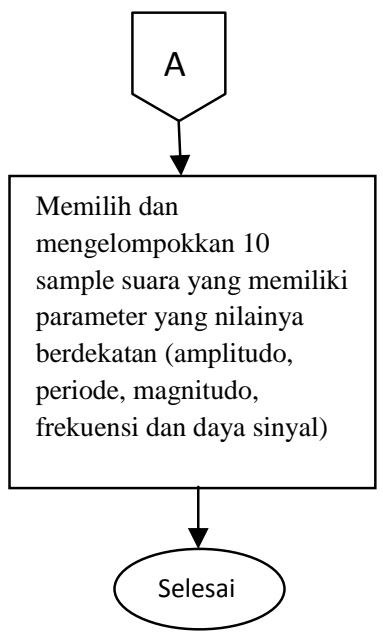

Gambar 2. Flowchart metode analisa ciri sampel suara wanita dan pria berbasis $F F T$

\section{Hasil Penelitian}

Berdasarkan 4 parameter utama yang menjadi tolok ukur proses pengklasifikasian suara wanita dan suara pria yaitu amplitudo, periode, magnitudo, dan daya sinyal, maka proses penentuan nilai parameter tersebut adalah sebagai berikut:

1. Contoh tampilan bentuk gelombang sampel suara1

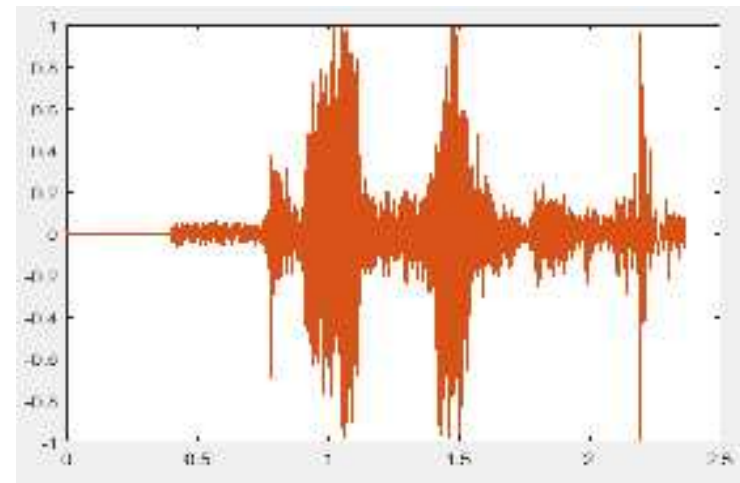

Gambar 3. Bentuk gelombang sampel suara1

2. Menentukan amplitudo rata-rata dari bentuk gelombang sampel suara1.

Pada gambar 3, terlihat ada 3 bentuk gelombang dengan nilai amplitudo tegangan maksimum rata-rata diambil yang mendekati, yaitu ada 3 nilai amplitudo tegangan maksimum yaitu 1, 0.8 dan 0.6. Cara menentukan nilai tersebut secara 
otomatis dengan source code matlab atau dapat juga menggunakan tool matlab yaitu data cursor, maka nilai amplitudo tegangan maksimum rata-rata dari sampel suara 1 adalah:

Amplitudo tegangan maksimum

Vmaks $=(1+0.8+0.6) / 3$

$$
=0.7 \text { Volt }
$$

Amplitudo tegangan puncak ke puncak

Vpp $=2 *$ Vmaks $=2 * 0.7=1.4$ Volt

3. Menentukan periode rata-rata dari bentuk gelombang sampel suara1.

Periode adalah waktu yang dibutuhkan untuk terbentuknya 1 gelombang / sinyal. Dengan cara yang sama dengan point 1 , maka nilai periode sampe suara 1 adalah $0.372,2.282$ dan 0.072 . Sehingga periode ( $\mathrm{T}$ ) rata-rata sample suara 1 adalah:

Periode $=(0.372+0.282+0.072) / 3$

$$
=0.242 \text { second }
$$

4. Menentukan magnitudo dengan aplikasi matlab.

Frekuensi sampling suara standar adalah $8000 \mathrm{~Hz}$, maka untuk menentukan nilai magnitude suara 1 , terlebih dahulu menghitung frekuensi dari hasil perhitungan periode, yaitu $\mathrm{f} 1=1 / \mathrm{T}=$ $1 / 0.242=4.132$. Sehingga nilai frekuensi sample suara 1 sebesar :

$$
\begin{aligned}
& \mathrm{f} 1=4.132 * 8000=33058 \mathrm{~Hz} \\
& \mathrm{f} 2=1200 \mathrm{~Hz}
\end{aligned}
$$

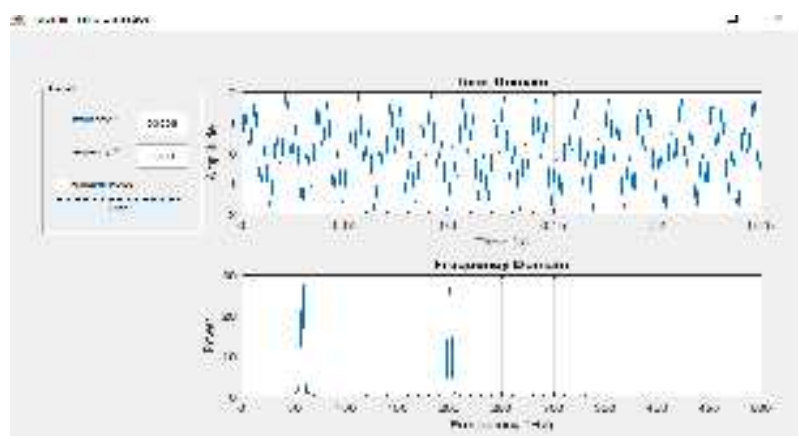

Gambar 4. Tampilan magnitude sinyal
Dari tool matlab (menggunakan data cursor), terlihat nilai magnitude sinyal ada 2 yaitu 30 dan 28, sehingga jika dirataratakan, akan diperoleh hasil sebagai berikut:

Magnitudo $=(30+28) / 2=29$

5. Menentukan daya sinyal.

Daya sinyal diperoleh dari perhitungan logaritma hasil perbandingan tegangan output dibagi dengan tegangan input. Pada sampel suara 1, tegangan output diperoleh dari nilai amplitudo sinyal dari point 1 yaitu 1.4 volt, sedangan tegangan input dianggap 1 volt (nilai standar), sehingga daya yang diperoleh adalah:

$$
\begin{aligned}
& \text { Daya }(\mathrm{dB})=20 \log _{10}(\text { Vout } / \text { Vin }) \\
& \text { Daya }(\mathrm{dB})=20 \log _{10}(1.4 / 1)=28 \mathrm{~dB}
\end{aligned}
$$

\begin{tabular}{|c|c|c|c|c|c|}
\hline Sampel & Bentuk sinyal & $\begin{array}{c}\text { Amplitudo } \\
\text { (Volt) }\end{array}$ & $\begin{array}{l}\text { Periode } \\
\text { (Second) }\end{array}$ & Magnitudo & $\begin{array}{l}\text { Daya } \\
(\mathrm{dB})\end{array}$ \\
\hline $\begin{array}{l}\text { Suara1 } \\
\text { (agung) }\end{array}$ & & 2 & 0.242 & 29 & 40 \\
\hline $\begin{array}{l}\text { Suara2 } \\
\text { (silfi) }\end{array}$ & & 0.849 & 0.765 & 30 & 16.9 \\
\hline $\begin{array}{l}\text { Suara3 } \\
\text { (ayu) }\end{array}$ & & 1.002 & 0.658 & 29 & 20.4 \\
\hline $\begin{array}{l}\text { Suara4 } \\
\text { (oji) }\end{array}$ & & 1.882 & 0.335 & 27 & 37.6 \\
\hline $\begin{array}{l}\begin{array}{l}\text { Suara5 } \\
\text { (andi) }\end{array} \\
\end{array}$ & & 1.976 & 0.538 & 29.75 & 39.5 \\
\hline $\begin{array}{l}\text { Suara6 } \\
\text { (irta) }\end{array}$ & & 0.826 & 1.190 & 30 & 16.5 \\
\hline $\begin{array}{l}\text { Suara7 } \\
\text { (hanif) }\end{array}$ & & 1.100 & 0.171 & 28 & 22 \\
\hline $\begin{array}{l}\text { Suara8 } \\
\text { (Reza) }\end{array}$ & $\sqrt{4}$ & 1.144 & 0.448 & 28 & 22.9 \\
\hline
\end{tabular}

Dengan tahapan yang sama, maka hasil uji sampel suara lainnya disajikan pada table 1 berikut :

Tabel 1. Hasil uji 10 sampel suara manusia 
JURNAL TEKNOLOGI TERPADU VOL. 7 NO. 2

\begin{tabular}{|l|c|c|c|c|c|}
\hline $\begin{array}{l}\text { Suara9 } \\
\text { (sari) }\end{array}$ & $\begin{array}{l}\text { n... } \\
\text { Suara10 } \\
\text { (maulia) }\end{array}$ & 1.003 & 1.037 & 30 & 20.1 \\
& $\vdots \ldots$ & 1.002 & 0.540 & 28 & 20.4 \\
\hline
\end{tabular}

Berdasarkan hasil pengujian 10 sampel suara, yang terdiri atas :

1. Suara pria sebanyak 5 sampel, yaitu suara1, suara 4, suara 5 , suara 7 dan suara 8.

2. Suara wanita sebanyak 5 sampel, yaitu suara 2, suara 3, suara 6, suara 9 dan suara 10.

Adapun parameter yang digunakan sebagai tolok ukur untuk mengklasifikasikan antara suara pria dan suara wanita adalah amplitude, periode, magnitude dan daya (power). Ternyata dari ke-4 parameter tersebut, hanya 2 parameter yang sangat akurat dalam membedakan antara suara pria dan suara wanita, yaitu amplitudo dan daya (power). Sedangkan parameter magnitude dan periode kurang akurat dalam membedakan antara suara pria dan suara wanita.

Berdasarkan hasil pengujian 10 sampel suara yang disajikan pada tabel 1 untuk pengucapan "Pengolahan Sinyal", dapat disimpulkan bahwa :

1. Suara pria memiliki amplitudo pada range (1.1 volt sampai 2 volt), dan daya pada range $(22 \mathrm{~dB}$ sampai $40 \mathrm{~dB})$.

2. Suara wanita memiliki amplitude pada range (0.826 volt sampai 1.003 volt), dan daya pada range (16.5 dB sampai $20.4 \mathrm{~dB}$ ).

Hal ini berarti bahwa amplitudo suara pria lebih tinggi daripada suara wanita sehingga daya (power) suara pria dinyatakan cenderung lebih tinggi daripada daya (power) suara wanita.

\section{Kesimpulan}

Berdasarkan hasil analisa pada penelitian ini, maka dapat ditarik kesimpulan sebagai berikut:

Amplitudo suara pria lebih tinggi daripada suara wanita yaitu untuk pria amplitudonya berada pada range (1.1 volt sampai 2 volt) sedangkan wanita memiliki amplitudo yang berada pada range (0.826 volt sampai 1.003 volt), sehingga daya (power) suara pria dinyatakan cenderung lebih tinggi daripada daya (power) suara wanita.

\section{Saran}

Saran yang diperlukan dalam penelitian ini adalah sebagai berikut:

1. Untuk penelitian selanjutnya, sebaiknya jumlah sampel ditambah. Semakin banyak jumlah sampel, maka hasil pengujian semakin akurat dan errornya mendekati nol.

2. Metode pengujian untuk penelitian selanjutnya sebaiknya pengambilan sampel suara dilakukan pada penekanan ucapan dan durasi waktu yang sama, untuk menghasilkan hasil pengujian yang sempurna.

\section{Daftar Pustaka}

[1] S. R.Y., Simulasi Sistem Pengacak dengan metode FFT (Fast Fourier Transform), Manado: E-Journal Teknik Elektro dan Komputer, 2014.

[2] H. R.J., 2015. [Online]. Available: http://hanifroikhatul-fst12.web.unair.ac.id/artikel_detail137516-FISIKA\%20KOMPUTASI\%202015FAST\%20FOURIER\%20TRANSFORM.html..

[3] R. Mulyani, "Pemetaan duara Manusia menggunakan Fast Fourier Transform (FFT)," 2017.

[4] D. F. H. J. Gunawan, Pengolahan Sinyal 
Digital, Yogyakarta: Graha Ilmu, 2012.

[5] V. J. G. P. K.Ingle, Digital Signal Processing using matlab, Stamford, 2012.

[6] ABDI, "Tingkat Kebisingan Suara," 2019. 